\title{
Simplifying pastoral systems modelling - accounting for the effect of urine deposition on $\mathrm{N}$ leaching
}

\author{
$\underline{\text { R. Cichota }}^{a}$ and V. O. Snow ${ }^{b}$ \\ ${ }^{a}$ AgResearch - Grasslands Research Centre, Palmerston North, New Zealand \\ ${ }^{b}$ AgResearch - Lincoln Research Centre, Lincoln, New Zealand \\ Email: Rogerio.Cichota@agresearch.co.nz
}

\begin{abstract}
Models are increasingly being used to assess the performance of farming systems. Computer modelling is a cost-effective way to study a wide range of factors and the only way to consider future scenarios. In pastoral systems, it is important to account for urine patches deposited by grazing animals as they are a major source of nitrogen $(\mathrm{N})$ leaching. Explicitly accounting for urine depositions is very challenging because the introduced spatial and temporal variability may require thousands of simulations depending on the system modelled. In this case the computing time becomes a significant limitation so there is a need for methods to reduce computing time of pastoral systems simulations.
\end{abstract}

Here we present an approach that can be used in the APSIM modelling framework to account for the effects of urine patches in a simplified way. Using a meta-model coded as an APSIM module, a fraction of the urine $\mathrm{N}$ deposited is removed from the simulation as direct urinary $\mathrm{N}$ leaching (Figure 1), the rest is retained in the simulation and is returned to the paddock evenly distributed as mineral N. This approach allows the user to model the whole paddock with relatively simple simulations, enabling to study a wide range of scenarios faster while still appropriately considering the impacts of urine depositions.

The proposed meta-model relates the fraction of $\mathrm{N}$ leached $\left(f_{L E A C H}\right)$ from urine patches to environmental and management factors. It was constructed using empirical functions derived from a comprehensive $\mathrm{N}$ leaching dataset, which was produced

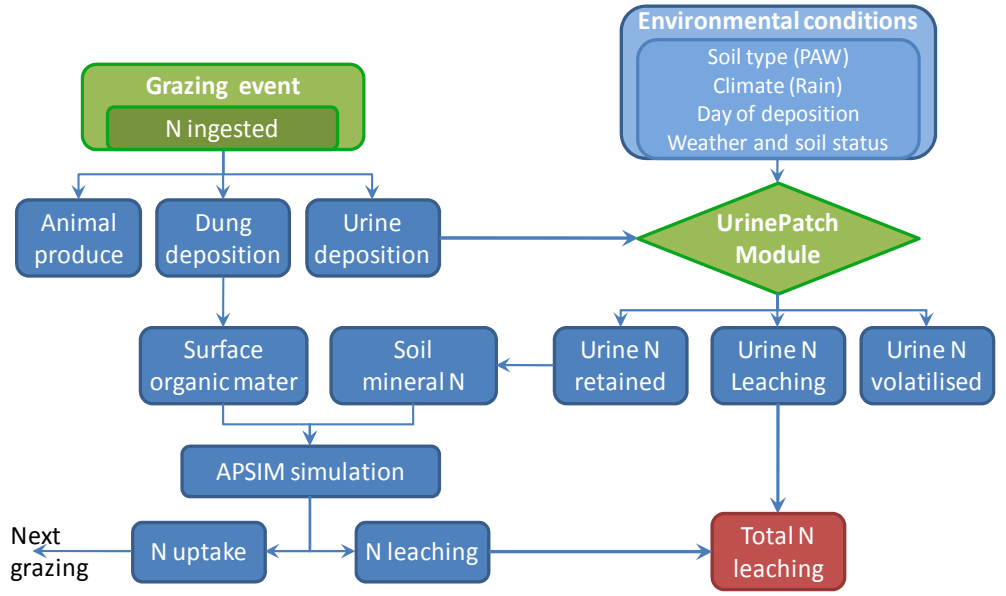

Figure 1. Schematic of the procedure used to simulate the effect of urine patch on $\mathrm{N}$ leaching. using simulations that explicitly described the urine patches. We present in this paper the results using data from the Canterbury region of New Zealand.

Stepwise regression and principal components analysis were used to identify the most important factors related to $f_{L E A C H}$ and then empirical functions were fitted to the dataset using regression analysis. This was performed in three steps to account for the major static factors (soil plant available water, urine $\mathrm{N}$ load, annual rainfall and day of urine deposition) and one step accounting for dynamic factors (average temperature on the week prior to urine depositions and soil moisture at the time of deposition).

Most of the variation was accounted for by the static factors, and the improvement by using dynamic factors was barely significant. This means that the meta-model lacks sensitivity to year-to-year variations, therefore it is better suited for long-term simulations. However, overall agreement was good $\left(\mathrm{R}^{2}=0.73\right)$, with little overall bias. The approach is thus promising, capturing the effects from the largest drivers of $\mathrm{N}$ leaching while considerably reducing the simulation time.

Keywords: Model simplification, heterogeneous excreta return, grazing systems modelling, APSIM model framework; 


\section{INTRODUCTION}

Nutrient losses from agricultural fields are deemed responsible for the increasing degradation of water quality in catchments dominated by farming (Elliott et al., 2005; Monaghan et al., 2005). The diffuse nature of such losses makes them difficult to measure, which in turn complicates the identification of sources as well as management options to reduce the losses. Computer simulations can be a cost-effective alternative for such analyses. However, modelling complex pastoral systems can also become resource-constrained. Investigating long-term effects of changes in farm management may require running a very large number of simulations in order to account for the interactions and variations of management and environmental factors. This may result in thousands of simulations when using a full factorial approach. Limiting the number of factors considered will reduce the number of simulations but may result in loss of information or accuracy, although quasi-random sampling techniques (Campolongo et al., 2007; Helton and Davis, 2003) can be used to minimize these losses. The use of meta-models is another option to reduce the simulation time and thus widen the testing range (Adams, 2007; Kleijnen, 2001; Piñeros Garcet et al., 2006). Meta-models are simplified versions of complex models, built based only on few statistically significant relationships. Although accuracy may be compromised for specific conditions, the overall predictions are improved by the gain of information due to the wider range of factors that can be considered. Meta-models typically require less and simpler inputs compared to complex models and this can sometimes reduce uncertainties in modelling work at large spatial or temporal scales (e.g. Leterme et al., 2007; Young et al., 1996).

In agricultural systems with grazing animals, typical in New Zealand, the return of nitrogen $(\mathrm{N})$ via urine is the major source for N losses (Ball and Ryden, 1984; Di and Cameron, 2002; Haynes and Williams, 1993). Grazing ruminants collect $\mathrm{N}$ from the whole paddock and deposit it in patches which, for a typical dairy system, represent $2-3 \%$ of the area after one grazing day. As a consequence the $\mathrm{N}$ load is far in excess of the plant's nutrients needs. Estimating $\mathrm{N}$ losses ignoring urine patches will incur in large errors as well as accumulate bias arising from the varying fate of urinary $\mathrm{N}$ deposited in different seasons (Hutchings et al., 2007; Shepherd et al., 2011; Snow et al., 2009). Incorporating urine patches into process-based models is not trivial. The implicit complexity of grazing systems is amplified by the variability introduced by the urine patches, which varies in time through sequential grazings. The computing costs of handling such spatial and temporal variability have limited modelling urine patches explicitly to a few studies (Hutchings et al., 2007; Snow et al., 2009). Thus there is a need for methods to simplify the description of the effects of urine patches when modelling $\mathrm{N}$ losses in grazing farm systems.

In this paper we present an approach to be used within the APSIM model framework which, in a simplified way, accounts for the effects of urine patches on $\mathrm{N}$ leaching. This allows the simulation of the whole paddock with a much simpler description than would be required to otherwise explicitly consider each of the urine depositions generated each grazing. To build our module, we have derived an empirical function based on meta-analyses of a comprehensive dataset produced by explicitly simulating urine patches using the process-based soil module SWIM. For this paper results using environmental data from the Canterbury region in New Zealand is presented.

\section{MODULE DEVELOPMENT}

\subsection{The APSIM framework}

The work described in this paper was developed using the APSIM (Agricultural Production Systems Simulator) modelling framework (Keating et al., 2003). APSIM is a modular framework which is ideal for multi-party development. Depending on the simulation type, the user can choose to use different modules, each one responsible for a part of the simulation (e.g. handling weather data, simulating the carbon and nitrogen cycle in the soil, etc.). Custom-made modules can be used to add functionality or as an alternative to existing modules. Modules particularly relevant to the work presented in here include SoilN (Probert et al., 1998) to simulate soil $\mathrm{C}$ and $\mathrm{N}$ transformation, and AgPasture (Li et al., 2010) for pasture growth and $\mathrm{N}$ uptake. To simulate soil water and solute movement APSIM has two standard modules, SWIM (Huth et al., 1996; Verburg et al., 1996) which uses a detailed approach that solves the numerical versions of the Richards' and convection-dispersion equations, and the simpler SoilWat (Probert et al., 1998) which uses a layered tipping-bucket approach. To describe the processes within a urine patch the SWIM module is preferred as it accounts for non-linear concentration-dependent processes ignored in SoilWat but which are important in the urine patches where $\mathrm{N}$ load can be very high (several times that of a fertilizer application for example). However, SWIM requires more parameters than does SoilWat and the highly non-linear numerical equations in SWIM means that sub-daily time-steps must be used (this will depend on the non-linearity of the equation describing the soil properties) which considerably increases the computing time. In addition the equations may fail to converge at any point in the simulation causing the simulation to fail. The differences 
in parameterisation and computing costs explain why SoilWat is the preferred soil module for most simulations using APSIM.

The APSIM model with the configuration used here has already been successfully used to describe results from experiments simulating urine deposition in both lysimeters and small plot experiments (Cichota et al., 2010; Snow et al., 2011).

\subsection{The UrinePatch module concept}

To account for the effects of urine patches on the amount of $\mathrm{N}$ leached from grazed paddocks, a module was built using empirical functions derived from meta-analyses of an $\mathrm{N}$ leaching dataset. The functions describe the relationships between several environmental factors and the fraction of the $\mathrm{N}$ deposited in urine patches that ultimately leaches. This fraction leached $\left(f_{L E A C H}\right)$ is defined as:

$$
f_{L E A C H}=\frac{N_{L E A C H, U}-N_{L E A C H, 0}}{N_{L O A D}}
$$

where $N_{L E A C H, U}$ is the amount leached from a urine patch, $N_{L E A C H, 0}$ is the leaching from the area without urine deposition, and $N_{L O A D}$ is the load of urine $\mathrm{N}$ deposited within the urine patch area. All values are in $\mathrm{kg} \mathrm{N} / \mathrm{ha}$, at $1.5 \mathrm{~m}$ depth and over the three years after deposition that is assumed to be the maximum life-span of a urine patch. The meta-model is composed of the set of functions describing $f_{L E A C H}$ and has been coded as an APSIM module, called UrinePatch.

During an APSIM simulation, after a grazing event, the amount of $\mathrm{N}$ ingested by the animals is partitioned into animal product and excreta (Figure 1). The amount of urine is sent to the UrinePatch module where a fraction is removed, being output as urine $\mathrm{N}$ leaching. The module also computes an estimate of $\mathrm{N}$ volatilisation. The remaining fraction is then returned to the soil mineral pool and the simulation continues to the next grazing event (Figure 1).

\subsection{Developing the meta-model for $f_{L E A C H}$ :}

\section{Urinary N leaching dataset}

A comprehensive set of simulations was used to produce a dataset of $\mathrm{N}$ leaching from urine patches under a diverse range of management and environmental factors. The dataset was built by combining the results from two simulation runs, each a factorial combination of weather data, soil type, irrigation, $\mathrm{N}$ load, and urine deposition time (Table 1). The seven different soils used in the first run were a subset of the fifty-two soils used in the second one. Likewise, the four weather data locations of the second run are a sample from the twenty-five locations of the first run. Both the weather and soil subsets were chosen to reflect the variation of the full data. Weather data for the 25 locations within the Canterbury plains in New

Table 1. Management and environmental factors varied in the two simulation runs used to develop the urinary $\mathrm{N}$ leaching dataset.

\begin{tabular}{lcc}
\hline Factor & Run 1 & Run 2 \\
\hline Weather location & 25 & 4 \\
Soil type & 7 & 52 \\
Irrigation & 2 (yes/no) & 1 (yes) \\
N load (kg N/ha) & $300 ; 600 ; 1000$ & $300 ; 500 ; 1000$ \\
Deposition month & 12 & 12 \\
Deposition year & 25 & 15 \\
& $(1980-2004)$ & $(1989-2003)$ \\
\hline
\end{tabular}
Zealand were obtained using the Virtual Climate Stations from NIWA (Tait et al., 2006). The fifty-two soils reflected the natural variability in the region. The parameters were derived based on the functional horizons approach (Webb, 2003) using data from the New Zealand Soils Database (Wilde, 2003). For these simulations the SWIM module was employed.

APSIM simulations were set using all combinations of the factors in Table 1. Separate simulations were run for each urine deposition, which occurred on the $15^{\text {th }}$ of each month and for each of the deposition years. The pasture was managed as cut-and-carry (thus without temporal overlap of urine depositions). The paddocks received $125 \mathrm{~kg} \mathrm{~N} / \mathrm{ha}$ as urea fertiliser, in ten applications between August and May. Irrigation was set using typical management for a centre-pivot irrigation system as is common in the region. $\mathrm{N}$ leaching was summed for three years after the urine deposition to ensure all leaching from the urine was accounted for. Parallel simulations ran without urine deposition to identify $\mathrm{N}$ leaching under the same conditions but without the urine patch. 


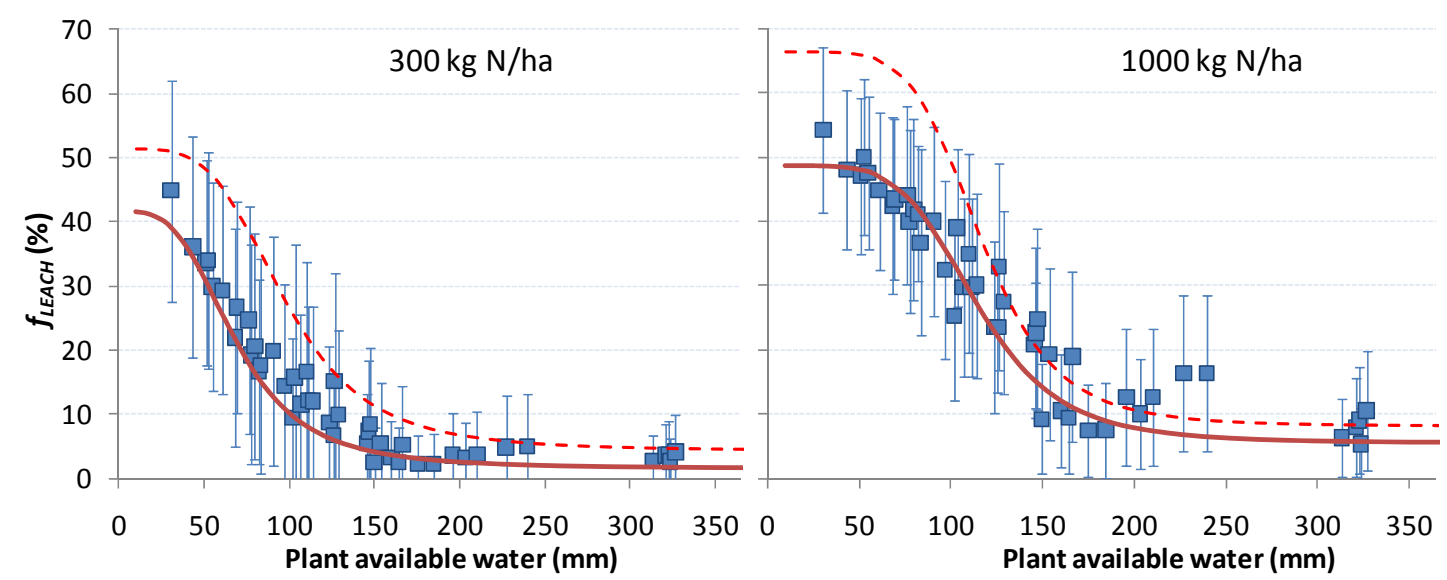

Figure 2. Simulated (symbols) and fitted (lines) values of $f_{L E A C H}$ as function of total soil plant available water, for irrigated sites and two different urine $\mathrm{N}$ loads. The dashed lines are the fit for non irrigated sites and are shown for comparison. The error bars show one standard deviation of simulated $f_{L E A C H}$.
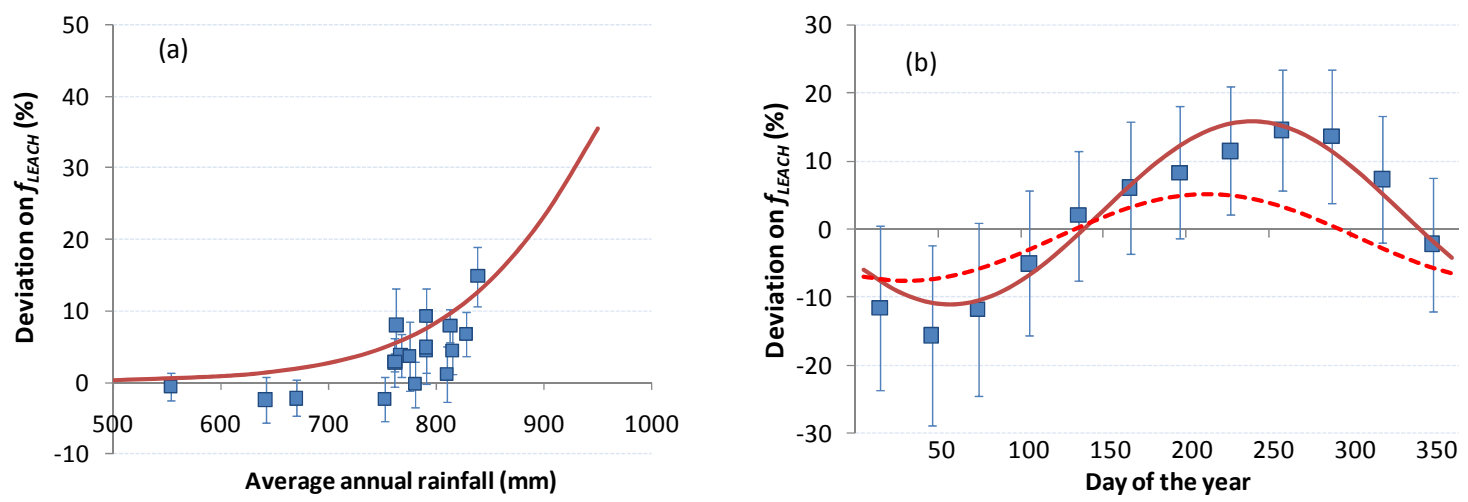

Figure 3. Simulated (symbols) and fitted (lines) values of the deviation of $f_{L E A C H}$ as a function of average annual rainfall (a) and day of deposition (b) all for sites irrigated with an N load of $500 \mathrm{~kg} \mathrm{~N} / \mathrm{ha}$. The error bars represent one standard deviation. The dashed line in (b) is the fit for non-irrigated sites.

\section{Identifying the driving factors}

A comprehensive set of environmental factors was attached to the $\mathrm{N}$ leaching dataset to assist with the analyses. These factors can be grouped into static factors, such as soil characteristics (bulk density, clay content, plant available water) and climate variables (annual rainfall, long-term average temperature, etc.), and dynamic factors, such as the soil moisture at the time of deposition, the amount of rainfall in the week prior to deposition, etc. To identify the most important factors related to variation in $f_{L E A C H}$, the dataset was subjected to stepwise regression as well as principal component analysis. The factors that showed most influence were chosen for building the empirical functions. Discernment was used in cases where the results were unclear or contradictory.

\section{Deriving the empirical functions}

After identifying the major environmental and management factors, regression analysis was used to derive the functions relating the fraction of $\mathrm{N}$ leached from urine patches to the environmental variables. Appropriate functions were identified and fitted in a sequence of three steps with each subsequent step applied to the residuals from the previous step. Thus the final value for $f_{L E A C H}$ is the sum of these successive adjustments, each accounting for the effects of one or two variables.

The first step accounted for the effects of urine $\mathrm{N}$ load and the plant available water in the soil. A sigmoid function was used to relate $f_{L E A C H}$ to plant available water (Figure 2) while both of its sills were related to the $\mathrm{N}$ load. The next two steps considered the effect of average annual rainfall (Figure 3a) and the time of urine deposition (Figure $3 \mathrm{~b}$ ). The later was also related to $\mathrm{N}$ load. Note that these adjustments used the deviations of $f_{L E A C H}$, or residues, after the model fitting in step one. All the fitting was done for irrigated and nonirrigated sites separately. These steps accounted for the primary static factors and encompassed most of the variation in $f_{L E A C H}$. 
Finally the two most relevant dynamic factors were used to complete the description of $f_{L E A C H}$. These were the average air temperature over the week prior to urine deposition and the soil water content (expressed as fraction of the plant available water) at the day of deposition (Figure 4). The function used to fit this data used both factors together, as their effect was found to be correlated. Again, for this adjustment the data from irrigated and non-irrigated sites were treated separately.

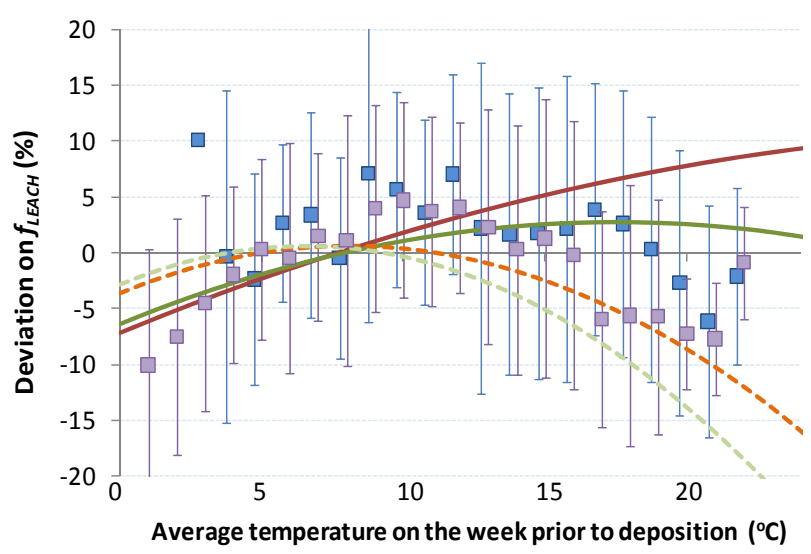

Figure 4. Simulated (symbols) and fitted (lines) values of the deviation of $f_{L E A C H}$ as a function of average temperature in the week prior to deposition. Information is shown for two levels of soil moisture; 50\% (blue symbols and red lines) and 100\% (purple symbols and green lines) of plant available water. Data is from patches of $\mathrm{N}$ load of $500 \mathrm{~kg} \mathrm{~N} / \mathrm{ha}$ at irrigated sites. The error bars represent one standard deviation. The dashed lines show the fit for non-irrigated sites, for comparison.

\subsection{Evaluation of the meta-model fit}

The meta-model, built with the functions fitted in the four steps describe above, showed good descriptive power when compared to the simulated $\mathrm{N}$ leaching dataset. Despite the large variability that characterises $\mathrm{N}$ leaching from soils, the value of $\mathrm{R}^{2}$ for all available data points was 0.729 . Also, there was very little overall bias, with average of calculated $f_{L E A C H}$ equal to 25.5 compared to 26.0 of the original data. Computing longterm averages across sites or soil types resulted in very good agreement for both dryland and irrigated sites (Figure 5). However, the year-to-year variability is underestimated by the empirical model, which means that the sensitivity of the module to variations in specific years is limited. This lack of sensitivity is due to the limited improvement in the fit of $f_{L E A C H}$ in the final step, when the dynamic factors were included (Figure 4). Capturing more of the effect of dynamic factors will be the biggest challenge to further develop this approach.

\section{CONCLUSIONS AND RECOMMENDATIONS}

The meta-model presented in this paper showed promising results. Estimation of the likely fraction of $\mathrm{N}$ leached from urine patches agreed reasonably well with the results from the simulations explicitly describing urine depositions. The module developed allows a user to run APSIM simulations at a paddock scale and still capture the effects of urine patches. This enables users to run a wide range of scenarios in a feasible time-frame. The proposed module does not fully capture all of the variability in $\mathrm{N}$ leaching but does represent the impacts of the major management and environmental factors with little bias. The empirical model does not provide any information about the timing of $\mathrm{N}$ leaching through a particular depth in the soil. Therefore, the approach used here is suitable for simulations of long-term trends rather than mimicking shortterm experiments. The loss in sensitivity of the empirical model may be well compensated by the extra factors or scenarios that can be tested using a less time consuming simulation setting.

Urine patches cannot be neglected when describing farm systems with a grazing component. The heterogeneity introduced by these patches is large and thus methods to simplify its description are needed. The meta-modelling approaches have been shown to be useful in several areas and certainly are promising in describing the effects of $\mathrm{N}$ leaching from urine patches. For the proposed module, further evaluation is required to determine its descriptive power at the paddock and farm levels. The usefulness of empirical functions is commonly restricted to the scope of the data they are derived from, thus the functions presented here also need to be tested for different environmental conditions, if they are to be used in other regions.

Irrigated

Averages across 15 years
Dryland

Averages across 25 years 


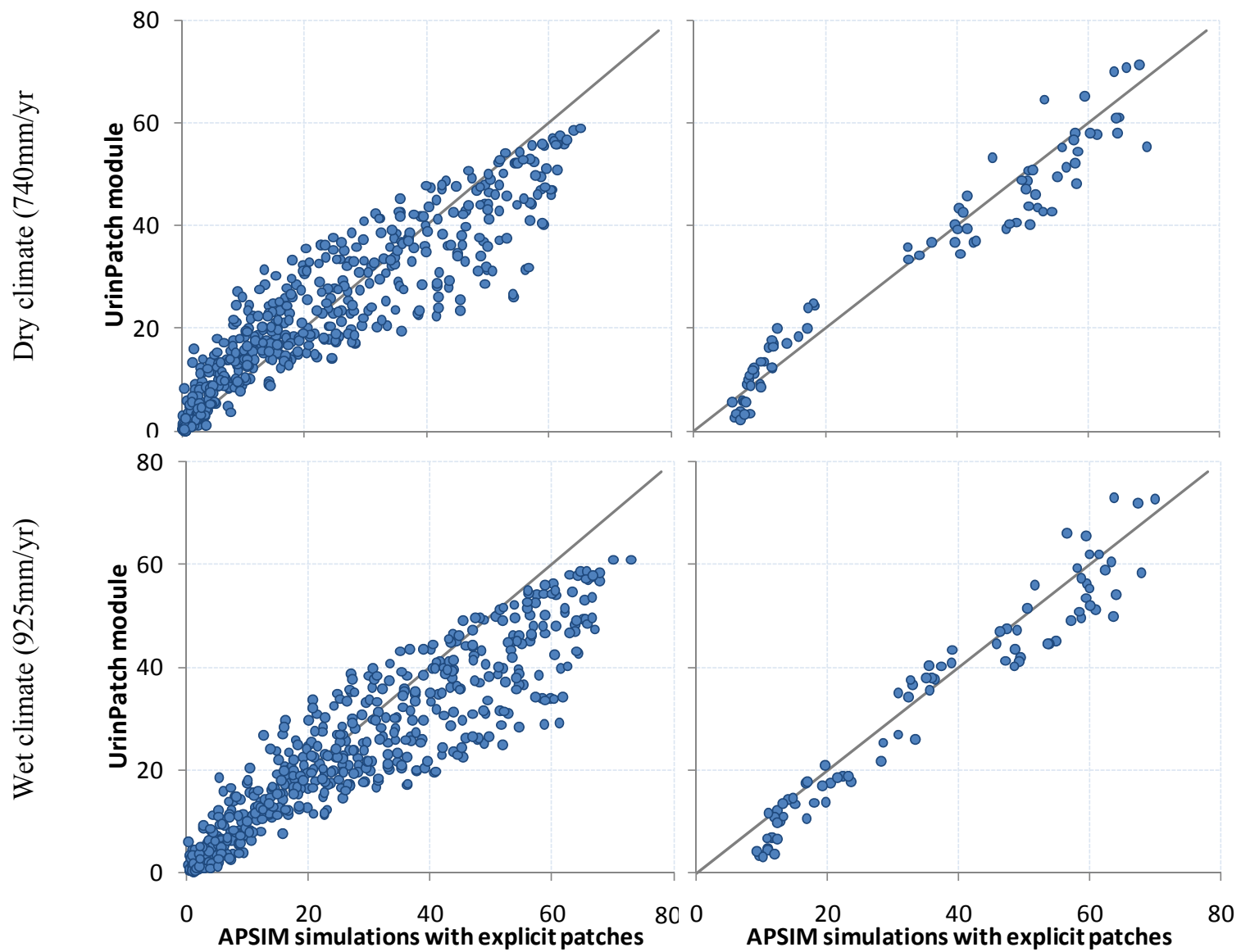

Figure 5. Comparison between the $f_{L E A C H}$ simulated by APSIM-SWIM with explicit urine patch deposition and calculated using the empirical functions developed for the UrinePatch module. Each dot represents the average across years for each soil type and month of deposition. The 1:1 line is also shown.

\section{ACKNOWLEDGMENTS}

The authors are grateful to Ben Jolly for the assistance with running and summarising the simulations used in this work. This work was funded by New Zealand Ministry of Science and Innovation under contract number C02X0812 "Land Use Change and Intensification"

\section{REFERENCES}

Adams, G.A. (2007). Towards an effective complexity for modelling nutrient generation from small catchments. In: Oxley, L.; and Kulasiri, D. (Eds). Proceedings of the MODSIM 2007 - International Congress on Modelling and Simulation, December 2007, University of Canterbury, Christchurch, New Zealand. pp. 2375-2381.

Ball, P.R. and Ryden, J.C. (1984). Nitrogen relationships in intensively managed temperate grasslands. Plant and Soil, 76(1-3), 23-33.

Campolongo, F., Cariboni, J., and Saltelli, A. (2007). An effective screening design for sensitivity analysis of large models. Environmental Modelling \& Software, 22(10), 1509-1518.

Cichota, R., Vogeler, I., Snow, V.O., and Shepherd, M. (2010). Describing the fate of high dose nitrogen in pastoral soils - Modelling N leaching under high N loads (urine patches). 19th World Congress of Soil Science, 1-6 Aug, 2010, Brisbane, Australia.

Di, H.J. and Cameron, K.C. (2002). Nitrate leaching in temperate agroecosystems: Sources, factors and mitigating strategies. Nutrient Cycling in Agroecosystems, 64(3), 237-256.

Elliott, A.E., Alexander, R.B., Schwarz, G.E., Shankar, U., Sukias, J.P.S., and McBride, G.B. (2005). Estimation of nutrient sources and transport for New Zealand using the hybrid mechanistic-statistical model SPARROW. Journal of Hydrology (New Zealand), 44, 1-27.

Haynes, R.J. and Williams, P.H. (1993). Nutrient cycling and soil fertility in the grazed pasture ecosystem. Advances in Agronomy, 49, 119-199.

Helton, J.C. and Davis, F.J. (2003). Latin hypercube sampling and the propagation of uncertainty in analyses of complex systems. Reliability Engineering and System Safety, 81(1), 23-69. 
Hutchings, N.J., Olesen, J.E., Petersen, B.M., and Berntsen, J. (2007). Modelling spatial heterogeneity in grazed grassland and its effects on nitrogen cycling and greenhouse gas emissions. Agriculture, Ecosystems \& Environment, 121(1-2), 153-163.

Huth, N.I., Keating, B.A., Bristow, K.L., Verburg, K., and Ross, P.J. (1996). SWIMV2 in APSIM: An integrated plant, soil water, and solute modelling framework. 8th Australian Agronomy Conference, Toowoomba, Australia. pp. 667.

Keating, B.A., Carberry, P.S., Hammer, G.L., Probert, M.E., Robertson, M.J., Holzworth, D., Huth, N.I., Hargreaves, J.N.G., Meinke, H., Hochman, Z., McLean, G., Verburg, K., Snow, V., Dimes, J.P., Silburn, M., Wang, E., Brown, S., Bristow, K.L., Asseng, S., Chapman, S., McCown, R.L., Freebairn, D.M., and Smith, C.J. (2003). An overview of APSIM, a model designed for farming systems simulation. European Journal of Agronomy, 18(3-4), 267-288.

Kleijnen, J.P.C. (2001). Experimental designs for sensitivity analysis of simulation models. In: Heemink, A.; and Dekker, L. (Eds). Proceedings of the $4^{\text {th }}$ International Eurosim 2001 Congress, June 2001, Delft.

Leterme, B., Vanclooster, M., van der Linden, A.M.A., Tiktak, A., and Rounsevell, M.D.A. (2007). The consequences of interpolating or calculating first on the simulation of pesticide leaching at the regional scale. Geoderma, 137(3-4), 414-425.

Li, F.Y., Snow, V.O., Holzworth, D., and Johnson, I.R. (2010). Integration of a pasture model into APSIM. In: Dove, H.; and Culvenor, R.A. (Eds). Proceedings of the 13th Australian Agronomy Conference, November, 2010, Lincoln, New Zealand.

Monaghan, R.M., Paton, R.J., Smith, L.C., Drewry, J.J., and Littlejohn, R.P. (2005). The impacts of nitrogen fertilisation and increased stocking rate on pasture yield, soil physical condition and nutrient losses in drainage from a cattle-grazed pasture. New Zealand Journal of Agricultural Research, 48(2), 227-240.

Piñeros Garcet, J.D., Ordoñez, A., Roosen, J., and Vanclooster, M. (2006). Metamodelling: Theory, concepts and application to nitrate leaching modelling. Ecological Modelling, 193(3-4), 629-644.

Probert, M.E., Dimes, J.P., Keating, B.A., Dalal, R.C., and Strong, W.M. (1998). APSIM's water and nitrogen modules and simulation of the dynamics of water and nitrogen in fallow systems. Agricultural Systems, 56(1), 1-28.

Shepherd, M., Phillips, P., and Snow, V.O. (2011). The challenge of late summer urine patches in the waikato region. In: Currie, L.D.; and Christensen, C.L. (Eds). Adding to the Knowledge Base for the Nutrient Manager - Occasional Report No. 24. Palmerston North, NZ: Fertiliser and Lime Research Centre, Massey University.

Snow, V.O., Johnson, I.R., and Parsons, A.J. (2009). The single heterogeneous paddock approach to modelling the effects of urine patches on production and leaching in grazed pastures. Crop and Pasture Science, 60(7), 691-696.

Snow, V.O., Shepherd, M., Cichota, R., and Vogeler, I. (2011). Urine timing: are the 2009 waikato results relevant to other years, soils and regions? In: Currie, L.D.; and Christensen, C.L. (Eds). Adding to the knowledge base for the nutrient manager - Occasional Report No.24. Palmerston North, New Zealand: Fertilizer and Lime Research Centre, Massey University. pp. 14.

Tait, A., Henderson, R., Turner, R., and Zheng, X.G. (2006). Thin plate smoothing spline interpolation of daily rainfall for New Zealand using a climatological rainfall surface. International Journal of Climatology, 26(14), 2097-2115.

Verburg, K., Ross, P.J., and Bristow, K.L. (1996). SWIMv2.1 User Manual. Divisional Report No 130. Canberra, Australia: CSIRO Division of Soils. 107 p.

Webb, T.H. (2003). Identification of functional horizons to predict physical properties for soils from alluvium in Canterbury, New Zealand. Australian Journal of Soil Research, 41(5), 1005-1019.

Wilde, R.H., (2003). Manual for National Soils Database, Landcare Research, Palmerston North. 53 p.

Young, P., Parkinson, S., and Lees, M. (1996). Simplicity out of complexity in environmental modelling: Occam's razor revisited. Journal of Applied Statistics, 23(2-3), 165-210. 